\title{
EFFECTS OF PROCESSING PARAMETERS ON THE MECHANICAL PROPERTIES OF ARAMID AIR TEXTURED YARNS FOR PROTECTIVE CLOTHING
}

\author{
Hyun Ah Kim¹, Seung Jin Kim² \\ ${ }^{1}$ Korea Research Institute for Fashion Industry, Daegu 701-170, Korea \\ ${ }^{2}$ Dept. of Textile Eng. and Technology, Yeungnam University, Gyeongsan 712-749, Korea
}

\begin{abstract}
:
This study examined the mechanical properties of a para-aramid filament according to the processing conditions of air-jet textured yarns (ATY). The specimens were prepared by changing the yarn speed, over feed ratio, air pressure, and heater temperature, which are important processing factors in the ATY process. The basic physical properties of the ATY, such as denier, tenacity, breaking strain, and initial modulus, were measured and their thermal shrinkage, such as dry and wet shrinkage, were measured to determine the thermal stability of the aramid ATY. In addition, the instability of para-aramid ATY were measured and assessed with the loop formation of ATY, according to the ATY process parameters. An examination of the effects of process parameters on the physical properties of aramid ATY revealed the core overfeed and air pressure to be the main factors. A high core overfeed and air pressure make the aramid ATY crimpy in the yarn core and entangle the fluffy loops on the yarn surface, resulting in an increase in the yarn linear density and breaking strain as well as a decrease in the tenacity and initial modulus. In contrast, these yarn physical properties were unaffected by the yarn speed, heater temperature, and wetting treatment. In addition, the dry and wet thermal shrinkage were unaffected by the process parameters of ATY. On the other hand, the instability decreased with increasing core overfeed and heater temperature and increased with increasing air pressure. These results showed that a high core overfeed makes the aramid ATY crimpy with an entangled yarn structure, and high air pressure helps provide small loops on the yarn surface. Finally, a high heater temperature makes the crimpy ATY structure more stable due to the strong heat set, which results in low instability.
\end{abstract}

\section{Keywords:}

para-aramid fiber, air-jet texturing, instability, core overfeed, air pressure

\section{Introduction}

The air-jet texturing process, which is a mechanical yarn bulking process, involves overfeeding a yarn by a supersonic air stream that develops loops and crimp, and then entangles the fiber in the yarn, resulting in a uniform arrangement of synthetic continuous multi-filament yarns. Loops developed on the yarn surface enhance the interactive forces with the imbedded resin, which increases the durability of the laminated protective clothing and provides fatigue resistance to the fiber-reinforced composites. In contrast to these advantages, considerable deterioration of the yarn tenacity and modulus is observed after texturing. Wang et al. [1] investigated the improvement in the tenacity and elongation of aramid yarns by ozone treatment. They studied the ozone treatment to improve the surface property of aramid fiber, which enables to overcome its very poor interfacial adhesion to most of the commercial resins, like the surface modification of carbon fibers using plasma technique. [2] On the other hand, Bilgin et al. [3] and Sengupta et al. [4] examined the air-jet texturing process and its physical properties with entangled loop formation on the air textured yarn surface. In addition, many studies have examined ways of overcoming the drawbacks of the yarn mechanical properties after air-jet texturing, [5-13] but their findings have been inconsistent. Furthermore, there are few reports related to the air-jet textured yarns composed of high tenacity and modulus filaments applicable to the protective clothing and fiber-reinforced composites. Zhang et al. [5] reported the effects of processing parameters, such as air pressure, texturing speed, under-feed ratio, and wetting, on the physical properties of diacetate air-jet textured yarns blended with polyester filaments. They [6] also examined the instability and boiling water shrinkage of diacetate/polyester air-jet textured yarns according to the over-feed ratios of the core and effect. Rengasamy et al. [7] examined the effects of the overfeed of core and effect, air pressure, wetting, and the feed yarn properties of polyester (FDY) on the yarn mechanical properties and instability. Acar et al. [8] re-examined the role of wetting, spin finish and friction in forming and fixing loops using a set of five different polyester and nylon supply yarns under the same texturing conditions. Mahish et al. [9] investigated the comfort and handle-related properties of polyester/viscose air-jet textured yarn fabrics. Gudiyawar et al. [10] studied the effects of the proportions of nylon/viscose blends on the characteristics of dry and pre-wet air-jet textured yarns. Baldua et al. [11] reported the effects of the feed yarn parameters, such as fineness, shape and total yarn linear density on the physical bulk, instability and strength of fully drawn PET air-jet textured yarns. Abromavicius et al. [12] and Chuah [13] studied the yarn bulk and the physical properties of polypropylene and poly trimethylene terephthalate (PTT) air-jet textured yarns, respectively. Recently, characterization 
of the air-jet textured yarn structure [14] was carried out by image analysis, and the bulkiness and hairiness of ATY [15] were also measured using image techniques. The difference in ATY physical properties between air-jet and steam jet [16-18] as well as color difference and physical properties according to the process parameters of ATY $[19,20]$ were evaluated based on the regression coefficient and analysis of variance. Aramid fibers, as a polyaromatic fiber, are classified as para and metaaramid fibers. The para-aramid fiber used in this study provides outstanding mechanical properties, such as high strength and elastic modulus, heat and cut resistance, and it can be supplied to a variety of products, such as industrial gloves, many types of protective clothing, and sports goods, and so on. Therefore, it has been applied widely to various technical textiles.

Aramid filaments treated with air-jet texturing improve the handle and ability to interact with imbedded resin through mechanical locking by the loop filament and crimp on the yarn surface than the filament state and thus enhance their function as reinforcements. On the other hand, the yarn physical properties of the aramid filaments tend to degrade after texturing. Several researchers [21-23] reported the effects of ATY process parameters on the physical properties of para-aramid ATY. Chaithanya [21] and Langston [22] examined the effects of process parameters on the mechanical properties of aramid air-jet textured yarns to understand how the air-jet textured yarn structure affects the delamination behavior of fiber-reinforced composites. Dani [23] examined the tensile properties of air-jet textured yarns using polyester tire cord, Dyneema, and aramid according to the air- jet processing parameters. Alagirusamy et al. [24] reviewed the relationship between air jet, filament yarn and processing parameters to improve the stability of hybrid yarns with highand low-modulus filaments. Mahmood et al. [25] described the physical properties of air textured glass yarns to improve the bonding strength of laminated composites according to the linear density of the core and effect, and air pressure. On the other hand, there is no consensus among their findings. Therefore, an investigation of the effects of ATY process parameters on the yarn physical properties of aramid ATY is needed before they can be applied to protective clothing, such as the racer clothing and industrial work wear, and fiber-reinforced composites. Therefore, this study examined the physical properties of para-aramid airjet textured yarns according to the processing conditions of ATY to identify the most suitable processing conditions for the final product.

\section{Experimental}

\subsection{Specimen Preparation}

Heracron ${ }^{\circledast}$ (brand name of the Kolon Industries INC, Korea), [26] as a para-aramid (PPTA, Poly-P-Phenylene Telephthal Amide), was used to prepare the specimens on a Tacsmack air-jet texturing machine (Korea) using a Heberlein Hemajet T351 nozzle. The linear density of yarn specimens used in this study was $1500 \mathrm{~d}$ composed with 1000 filaments. Figure 1 shows a schematic diagram of the air-jet texturing machine and

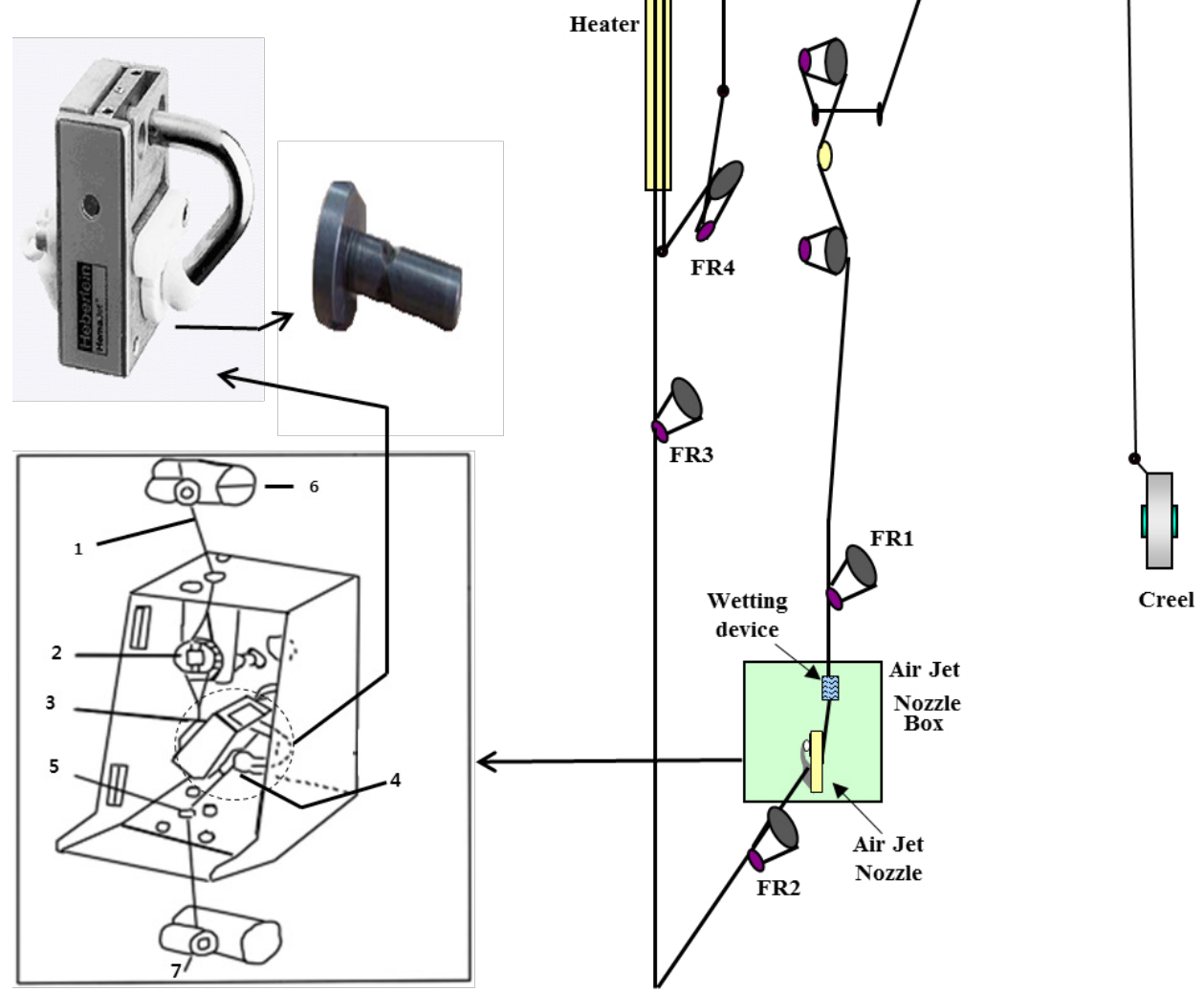

Figure 1. Schematic diagram of the air texturing machine. 
Hemajet T351 nozzle. Heracron para-aramid (1), as the core, was fed through the input feed roller and then wetted using a wetting device unit (2) with a $1.0 \mathrm{~L} / \mathrm{h}$ water consumption before entering the jet nozzle (3). The air-jet textured yarns from the Hemajet nozzle (3) were impacted with a baffle ball (4) and passed through the yarn guide (5). The core overfeed was adjusted by the ratio of surface velocity of the input feed roller (6) to that of the output roller (7). Table 1 lists the specimens according to the ATY process conditions. Specimens 1, 2, and 3 were prepared using three different yarn speeds under the following fixed conditions: core overfeed $(8.7 \%)$ and air pressure $\left(10 \mathrm{~kg} / \mathrm{cm}^{2}\right)$. Specimens 4 to 8 were prepared with 5 different core overfeeds, and specimens 9 to 13 were texturized with 5 different air pressures. Specimens 14 to 18 were prepared at 5 different heater temperatures under the following fixed conditions: speed $(220 \mathrm{~m} / \mathrm{min})$ and overfeed $(9.7 \%)$. Finally, specimen 19 was made with no water dipping under the following fixed conditions: yarn speed $(220 \mathrm{~m} / \mathrm{min})$, core overfeed $(8.7 \%)$, and air pressure $\left(10 \mathrm{~kg} / \mathrm{cm}^{2}\right)$.

\subsection{Measurement of the yarn physical properties}

The yarn physical properties, such as the yarn linear density, thermal shrinkage, and the tensile property of these specimens, were measured and the instability was also assessed using the Herberlein method. These yarn physical properties were verified with the yarn surface profile measured using a video microscope. The yarn linear density was measured by weighing $900 \mathrm{~cm}$ of each specimen wound on a wrap reel. Twenty readings were taken for each specimen; the mean, maximum, and minimum values were used to analyze the process variables. The tenacity, breaking strain, and modulus of the yarn specimens were measured with a gauge length of $100 \mathrm{~mm}$ and a crosshead speed of $100 \mathrm{~mm} / \mathrm{min}$ using a Testomeric MICRO 350. The wet thermal shrinkage was measured using a KSK0215. The hank of each specimen was prepared by winding ten turns of the yarn on a wrap reel at a tension of $0.01 \mathrm{~g} / \mathrm{d}$. The length of the skein $I_{o}$ was measured at an initial tension of $0.2 \mathrm{~g} / \mathrm{d}$. The length of the skein $l_{f}$ was measured again after placing the sample into a bath of boiling water for 30 minutes and dried for 24 hours under the same tension of $0.2 \mathrm{~g} / \mathrm{d}$. The dry thermal shrinkage was also measured using a heat chamber at $180^{\circ} \mathrm{C}$ as the same procedure, and the wet (dry) thermal shrinkage (\%) was estimated using equation (1):

Wet (dry) thermal shrinkage $(\%)=\left(I_{o}-I_{f}\right) / I_{o} \times 100 .(1)$

The yarn instability was measured using the Heberlein method. Fig. 2 presents a schematic diagram of the instability test method. [27] The length of the hank, a, was measured after loading approximately $0.01 \mathrm{~g} / \mathrm{d}$, and the length, $\mathrm{b}$, was measured after a $0.45 \mathrm{~g} / \mathrm{d}$ loading for 1 minute. The instability $\mathrm{I}(\%)$ was estimated using equation (2):

Table 1. Prepared para-aramid ATY specimens.

\begin{tabular}{|c|c|c|c|c|}
\hline \multicolumn{2}{|c|}{ Specimen } & \multicolumn{2}{|c|}{ Process conditions } & Fixed conditions \\
\hline \multirow{19}{*}{$\begin{array}{l}\text { Heracron } \\
\text { para-aramid } \\
1500 d / 1000 f\end{array}$} & 1 & \multirow{3}{*}{$\begin{array}{l}\text { Yarn speed } \\
(\mathrm{m} / \mathrm{min})\end{array}$} & 200 & \multirow{3}{*}{$\begin{array}{c}\text { Core O/F: } 8.7 \% \\
\text { Air pressure: } 10 \mathrm{~kg}_{\mathrm{f}} / \mathrm{cm}^{2} \\
\text { No heater, water wetted }\end{array}$} \\
\hline & 2 & & 220 & \\
\hline & 3 & & 250 & \\
\hline & 4 & \multirow{5}{*}{$\begin{array}{l}\text { Overfeed of Core } \\
(\%)\end{array}$} & 4.2 & \multirow{5}{*}{$\begin{array}{l}\text { Yarn speed: } 220 \mathrm{~m} / \mathrm{min} \\
\text { Air pressure: } 10 \mathrm{~kg}_{\mathrm{f}} / \mathrm{cm}^{2} \\
\text { No heater, water wetted }\end{array}$} \\
\hline & 5 & & 6.4 & \\
\hline & \multirow{2}{*}{$\frac{6}{7}$} & & 8.7 & \\
\hline & & & 11.1 & \\
\hline & 8 & & 13.6 & \\
\hline & 9 & \multirow{5}{*}{$\begin{array}{l}\text { Air pressure } \\
\left(\mathrm{kg}_{\mathrm{f}} / \mathrm{cm}^{2}\right)\end{array}$} & 7.5 & \multirow{5}{*}{$\begin{array}{c}\text { Yarn speed: } 220 \mathrm{~m} / \mathrm{min} \\
\text { Core O/F: } 8.7 \% \\
\text { No heater, water wetted }\end{array}$} \\
\hline & 10 & & 9 & \\
\hline & 11 & & 10 & \\
\hline & 12 & & 11 & \\
\hline & 13 & & 12 & \\
\hline & 14 & \multirow{5}{*}{$\begin{array}{l}\text { Heater temperature } \\
\qquad\left({ }^{\circ} \mathrm{C}\right)\end{array}$} & 150 & \multirow{5}{*}{$\begin{array}{c}\text { Yarn speed: } 220 \mathrm{~m} / \mathrm{min} \\
\text { Core O/F: } 8.7 \% \\
\text { Water wetted } \\
\text { Air pressure: } 10 \mathrm{~kg}_{\mathrm{f}} / \mathrm{cm}^{2}\end{array}$} \\
\hline & 15 & & 170 & \\
\hline & 16 & & 190 & \\
\hline & 17 & & 210 & \\
\hline & 18 & & 230 & \\
\hline & 19 & $\begin{array}{c}\text { No water } \\
\text { (not wetted) }\end{array}$ & & $\begin{array}{l}\text { Yarn speed: } 220 \mathrm{~m} / \mathrm{min} \\
\text { Core O/F: } 8.7 \% \text {, No heater } \\
\text { Air pressure: } 10 \mathrm{~kg}_{\mathrm{f}} / \mathrm{cm}^{2}\end{array}$ \\
\hline
\end{tabular}




$$
\text { Instability }(\%)=(b-a) / a \times 100
$$

The yarn surface profile was observed using a video microscope, SV55, SOMETECH.
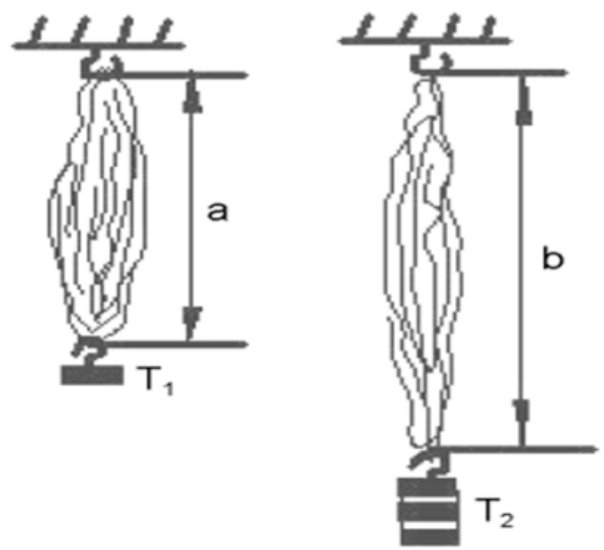

Figure 2. Schematic diagram of the instability tester. [6]

\section{Results and Discussion}

\subsection{Yarn linear density of ATY}

Table 2 lists the measured yarn physical properties of 19 ATY specimens. Figure 3 shows the yarn linear density of the paraaramid ATY according to the processing conditions of ATY.
The yarn linear densities decreased slightly with increasing feed speed of the yarn. This was attributed to the higher yarn speed causing an increase in tension subjected to the yarn in the axial direction and thus, the length of yarn became slightly longer in the axial direction, that is, decreasing yarn linear density, which showed a different result compared to an earlier report [27] that studied the aramid/nylon hybrid ATY. The yarn linear density increased with increasing overfeed of the yarn. This was attributed to the many loops developed on the yarn surface due to interlocking between the filament in the yarn at a higher overfeed ratio. Hence, the mass per unit length increased, as shown in the microscopy images of specimens 4 and 8 in Figure 3. Increasing the air pressure increased the yarn linear density due to an increase in the mass per unit length because of the relatively large number of loops formed by the high air pressure, which is shown in the microscopy images of specimens 9 and 13 in Figure 3. When the heater temperature was increased, loop formation was flatter due to the heat-set treatment, which might result in a lower yarn linear density. No change was found in the yarn linear density according to the wetting state, which was attributed to the slick property of the aramid filament. The linear density of the aramid air-jet textured yarns was mostly affected by the core overfeed and air pressure and slightly affected by the yarn speed and heater temperature due to high yarn mechanical and thermal properties of the aramid. In addition, wetting was unaffected by the yarn linear density because of the slick properties of the aramid.

Table 2. Measured yarn physical properties of the ATY specimens.

\begin{tabular}{|c|c|c|c|c|c|c|c|}
\hline \multirow{2}{*}{ Specimens } & \multirow{2}{*}{$\begin{array}{l}\text { Yarn linear } \\
\text { density (d) }\end{array}$} & \multicolumn{3}{|c|}{ Yarn mechanical property } & \multicolumn{2}{|c|}{$\begin{array}{c}\text { Thermal shrinkage } \\
(\%)\end{array}$} & \multirow{2}{*}{$\begin{array}{c}\text { Instability } \\
(\%)\end{array}$} \\
\hline & & $\begin{array}{c}\text { Tenacity } \\
\text { (g/d) }\end{array}$ & $\begin{array}{l}\text { Breaking } \\
\text { strain (\%) }\end{array}$ & $\begin{array}{c}\text { Initial } \\
\text { modulus (g/d) }\end{array}$ & Wet & Dry & \\
\hline 1 & 1590 & 8.6 & 17.0 & 99.7 & 0.2 & 0.4 & 1.08 \\
\hline 2 & 1589 & 9.3 & 18.6 & 98.4 & 0.4 & 0.4 & 0.81 \\
\hline 3 & 1566 & 9.9 & 17.0 & 105.4 & 0.73 & 0.94 & 1.35 \\
\hline 4 & 1542 & 13.0 & 14.2 & 182.1 & 0.2 & 0.33 & 1.62 \\
\hline 5 & 1556 & 12.0 & 15.8 & 142.2 & 0.27 & 0.4 & 1.35 \\
\hline 6 & 1588 & 10.6 & 16.8 & 116.4 & 0 & 0.13 & 1.35 \\
\hline 7 & 1582 & 9.7 & 18.1 & 94.7 & 0.13 & 0.4 & 1.28 \\
\hline 8 & 1608 & 9.1 & 21.1 & 76.4 & 0.4 & 0.4 & 0.87 \\
\hline 9 & 1480 & 15.6 & 10.2 & 277.4 & 0.07 & 0.27 & 0.67 \\
\hline 10 & 1500 & 14.5 & 12.0 & 248.2 & 0 & 0.54 & 0.87 \\
\hline 11 & 1500 & 10.7 & 12.2 & 161.9 & 0 & 0.2 & 0.67 \\
\hline 12 & 1565 & 8.4 & 16.1 & 92.0 & 0.2 & 0.07 & 0.94 \\
\hline 13 & 1580 & 8.1 & 17.2 & 82.6 & 0.13 & 0.53 & 1.42 \\
\hline 14 & 1540 & 11.3 & 15.0 & 149.9 & 0.27 & 0.13 & 0.94 \\
\hline 15 & 1540 & 11.3 & 13.4 & 156.0 & 0.13 & 0.07 & 1.08 \\
\hline 16 & 1535 & 11.2 & 14.5 & 154.8 & 0.13 & 0.07 & 0.94 \\
\hline 17 & 1530 & 11.8 & 13.7 & 173.8 & 0.13 & 0.27 & 0.74 \\
\hline 18 & 1520 & 12.0 & 14.0 & 166.8 & 0.2 & 0.33 & 0.71 \\
\hline 19 & 1568 & 10.4 & 17.9 & 116.1 & 0.13 & 0.2 & 1.01 \\
\hline
\end{tabular}



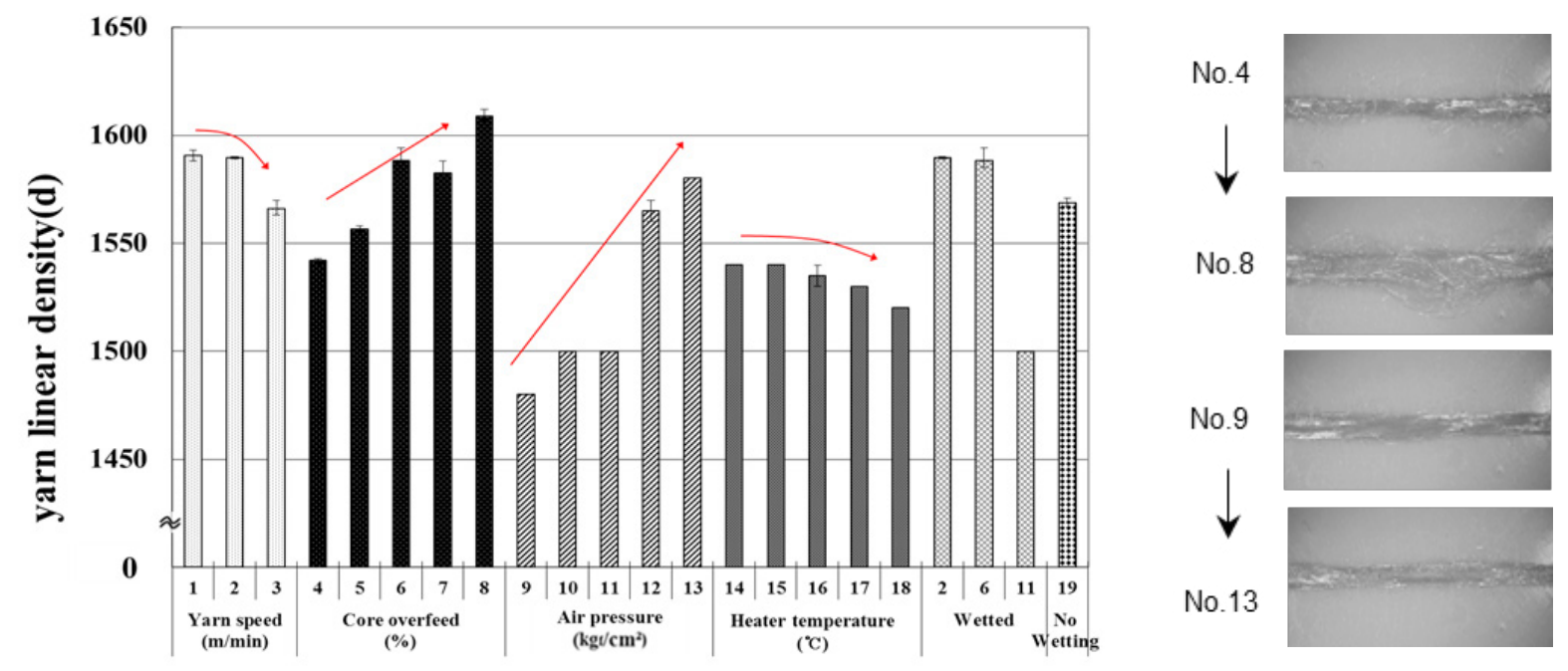

Figure 3. Yarn linear density of the para-aramid ATY according to the processing conditions of the ATY.

\subsection{Mechanical properties of the ATY}

Figure 4 shows the tensile properties, such as tenacity, breaking strain, and initial modulus of para- aramid ATY. As shown in Figure 4(a), the tenacity increased slightly by a value between 2 and $3 \mathrm{~g} / \mathrm{d}$ with increasing texturing speed. This is because when the speed increases, the length of the yarn becomes slightly longer in the axial direction and the filaments are parallel. In addition, there is less time for the air jet to act upon the filaments and thus, the loop formation will be less intensive and the fiber orientation will be disrupted to a lesser extent, which results in a high yarn linear density. The tenacity decreased with increasing core over feed. At a higher overfeed, there are greater bulk loops on the filament surface. As a result, the number of fibers to bear the tension was relatively small, which reduces the tenacity of ATY. The microscopy images in Figure 4(a) reveal specimen 8 to have a bulkier structure than specimen 4. According to a previous study, [8] a higher air pressure causes more loops that do not have good load bearing capacity because they are not aligned in the axial direction. In this experiment, the tenacity tended to decrease with increasing air pressure, which was caused by more loops on the yarn surface shown in the microscopy images in Figure 4(a), but not shown in the aramid/nylon ATY. [27] The change in heater temperature does not affect the tenacity, which appears to be due to the high thermal resistant property of the aramid. In addition, there was no difference in the tenacity of ATY between the wetting and non-wetted conditions because of the slick property of the aramid yarn surface. Figure 4 (b) shows the breaking strain of the para-aramid ATY. With increasing core overfeed ratio until $13.6 \%$, the breaking strain increased to $22 \%$. This can be explained by the larger extension due to the increase in entanglement by the high overfeed among the core filaments in the yarn. The breaking strain also increased from $12.5 \%$ to $17.5 \%$ with increasing air pressure due to the many loops on the yarn surface caused by the high pressure, which were observed in the microscopy images of the yarn surfaces in Figure 4(b). The breaking strain according to the yarn speed and heater temperature did not show any tendency. The breaking strain of the yarn treated with water showed no differences compared to the untreated yarn specimen with water, which is responsible for the high smoothness of aramid due to its slick property. Figure 4 (c) shows the initial modulus of the para-aramid ATY. The initial modulus decreased from $200 \mathrm{~g} / \mathrm{d}$ to $80 \mathrm{~g} / \mathrm{d}$ with increasing core overfeed due to an increase in entanglement among the filaments in the yarn and the size of the loop. [27] The initial modulus of the ATY decreased with increasing air pressure, which was also caused by the large number of loops on the yarn surface. These yarn structures were observed in the microscopy images of specimens 4 and 8 by the core overfeed, and in specimens 9 and 13 by the air pressure in Figure 4(c). The initial modulus did not show any clear trend with the changes in yarn speed, heater temperature and wet texturing. Among the aramid ATY processing parameters, the core overfeed and air pressure had the greatest effects on the yarn mechanical properties and the yarn speed, and the heater temperature did not affect the ATY mechanical properties due to the high strength and modulus, and high thermal resistant properties of the aramid.

\subsection{Thermal shrinkage of aramid ATY}

As shown in Table 2, the thermal shrinkage, according to the ATY process parameters, was less than $1 \%$ and no tendencies of the wet and dry thermal shrinkage according to the ATY process parameters were observed. This was attributed to the high thermal resistance of aramid, which resulted in thermal dimensional stability. According to an earlier study, [27] the dry thermal shrinkage of the nylon/aramid hybrid ATY yarns ranged from $3 \%$ to $6 \%$ according to the ATY process parameters and the wet thermal shrinkage ranged from $6.5 \%$ to $10 \%$, which were governed by the thermal shrinkage of the nylon filament.

\subsection{Instability of aramid ATY}

Figure 5 shows the instability of ATY according to the ATY process parameters. As shown in Figure 5, the instability decreased with increasing core overfeed. This was attributed to the large number of entangled loops with increasing core overfeed on the yarn surface, which was shown in the optical microscopy images of specimens 4 and 8 in Figure 5, resulting in the high stability of ATY. The instability decreased slightly with 

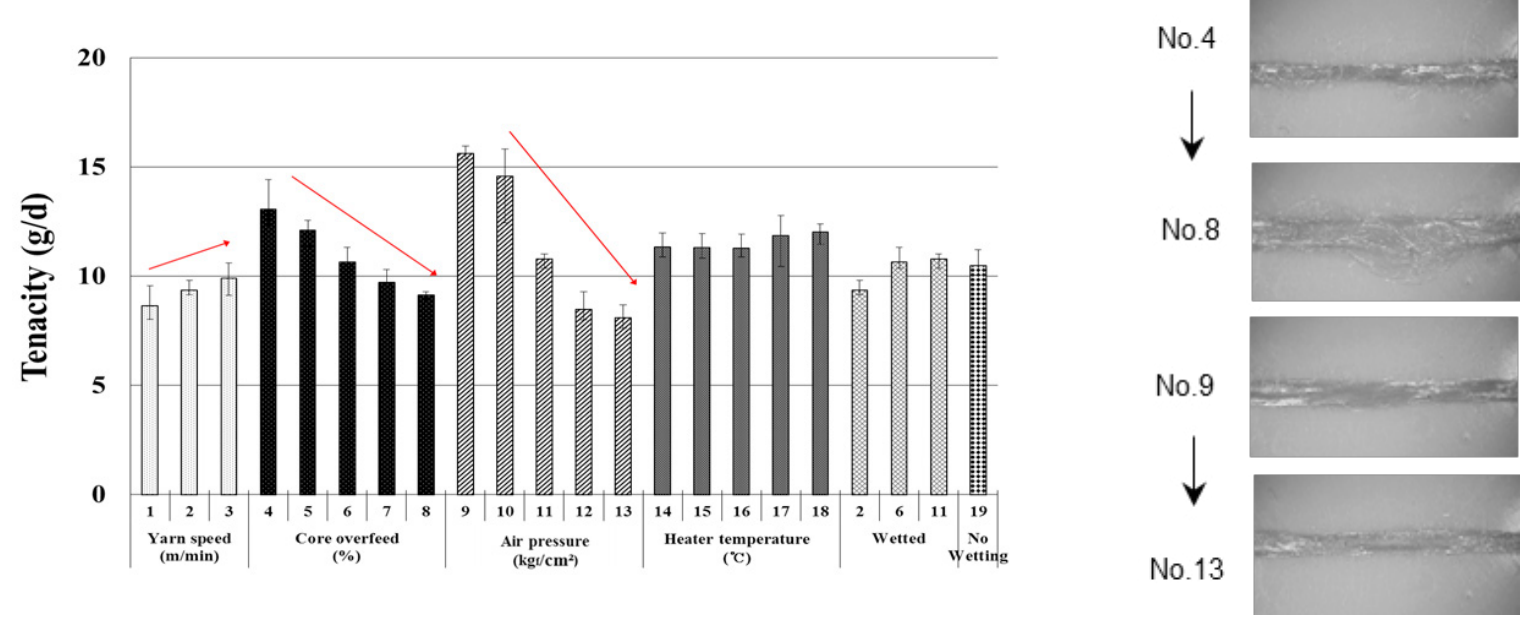

(a) Tenacity (g/d)
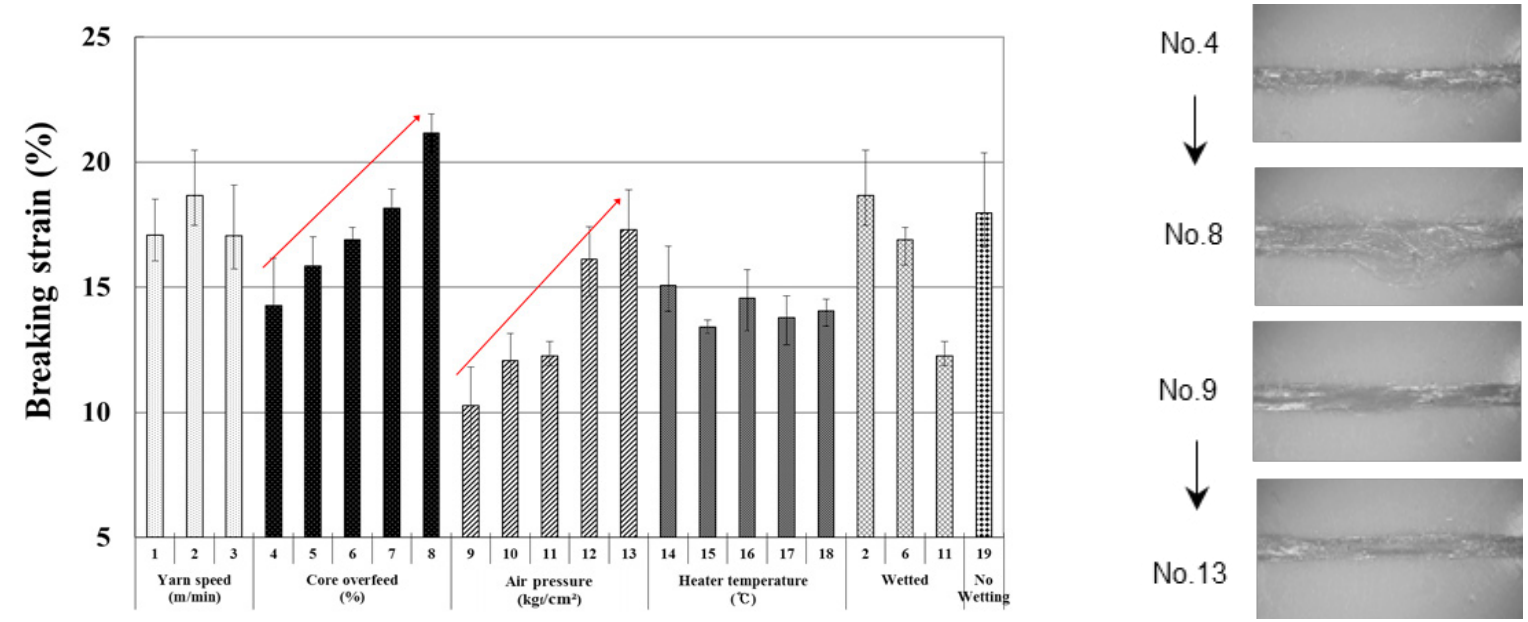

(b) Breaking strain (\%)
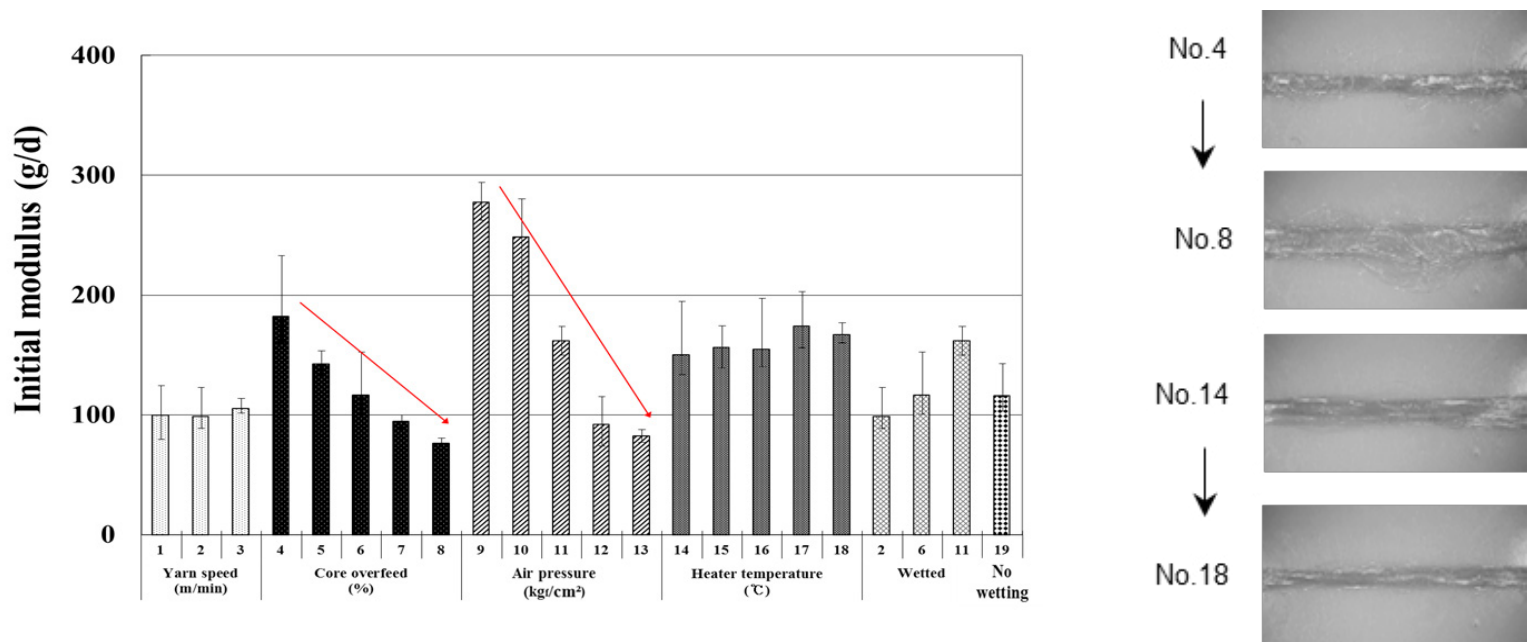

(c) Initial modulus (g/d)

Figure 4. Tensile properties of para-aramid ATY according to the processing conditions of ATY.

increasing heater temperature due to an increase in the flatness by the heat treatment, which is shown in the optical microscopy images of specimens 14 and 18 in Figure 5. These results are in contrast to the results of previous studies $[5,6,27]$ because of the difference in materials, that is, triacetate, polyester and nylon/ aramid in the previous studies $[5,6,27]$ and the $100 \%$ aramid of this study. On the other hand, the instability increased with increasing air pressure. A higher air pressure produces a large number of loops on the filament yarn surface. This was observed in the structure of yarn surface of specimens 9 and 13 in Figure 5 , which resulted in an increase in the yarn instability. Instability of the yarn did not show a clear trend with the change in yarn speed. This showed slightly different results to previous studies $[5,6,27]$ because of difference in the mechanical properties, such as bending and torsional rigidities between the regular filaments and aramid $100 \%$ filament, as triacetate, PET and nylon/aramid 

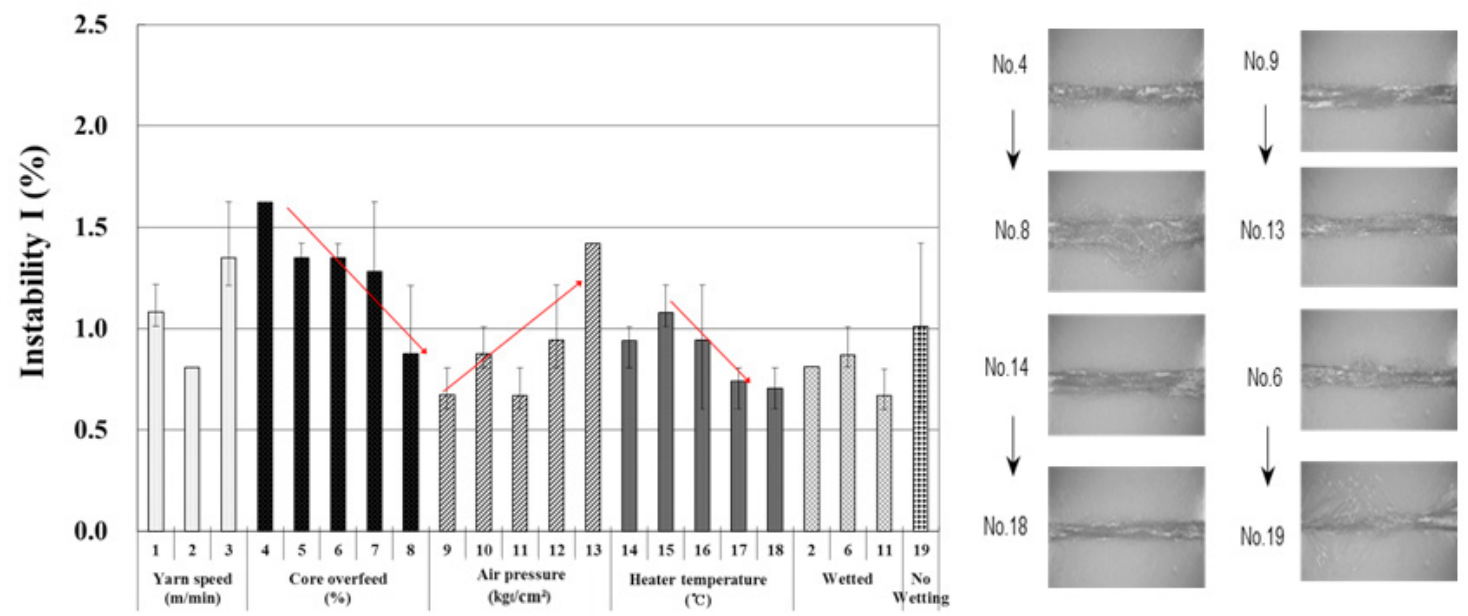

Figure 5. Instability of para-aramid ATY according to the processing conditions of the ATY.

were used in the previous study, $[5,6,27]$ and $100 \%$ aramid was used in the present study. On the other hand, there was no difference in instability between specimens 2,6 , and 11 with the water wetted and non-wetted specimen 19. This means that water acted as a lubricant to reduce the friction between the filaments in the wet texturing process and did not affect the yarn instability, which was caused by the high tenacity and modulus of the aramid filament. Furthermore, a decrease in friction due to the water between filaments in the ATY yarn did not affect the change in the yarn structure because of the high stiffness of aramid filament, which is shown in the yarn surface images of specimens 6 and 19 in Figure 5.

\subsection{Estimated aramid ATY model}

Figure 6 shows the ATY yarn surface profile measured by a video microscope (SV55, SOMETECH) according to the feed speed, core overfeed, air pressure, heater temperature, and no wetting.
As shown in Figure 6(a), when the feed speed was increased, slightly fluffy fibers were observed on the yarn surface and much more entangled loops (Figure 6(b) and 6(c)) were observed at a higher core overfeed ratio and air pressure. No difference between wetting and no wetting (Figure 6(e)) was observed, but a slightly large sized loop was shown on the wetting yarn. The core overfeed and air pressure were the key factors affecting the various yarn physical properties of the para-aramid ATY, which determine the crimp in the yarn core, and the entangled small loops were made on the yarn surface by the high air pressure in the nozzle. Based on these physical properties as per the ATY process parameters, the following estimated aramid ATY yarn structure is proposed, which is shown in Figure 7(b) and has been compared with the nylon/aramid hybrid ATY yarn model shown in Figure 7(a). [27] Table 3 lists the physical properties of aramid $100 \%$ ATY on the ATY process parameters.

Table 3. Physical properties of $100 \%$ aramid ATY on the ATY process parameters.

\begin{tabular}{|c|c|c|c|c|c|c|c|c|}
\hline $\begin{array}{l}\text { Process } \\
\text { parameter }\end{array}$ & & $\begin{array}{l}\text { Yarn linear } \\
\text { density(d) }\end{array}$ & $\begin{array}{c}\text { Tenacity } \\
\text { (g/d) }\end{array}$ & $\begin{array}{l}\text { Breaking } \\
\text { strain(\%) }\end{array}$ & $\begin{array}{c}\text { Initial } \\
\text { modulus } \\
(\mathrm{g} / \mathrm{d})\end{array}$ & $\begin{array}{c}\text { Dry heat } \\
\text { shrinkage } \\
\text { (\%) }\end{array}$ & $\begin{array}{c}\text { Wet heat } \\
\text { shrinkage } \\
\text { (\%) }\end{array}$ & $\begin{array}{c}\text { Instability } \\
(\%)\end{array}$ \\
\hline $\begin{array}{l}\text { Yarn speed } \\
(\mathrm{m} / \mathrm{min})\end{array}$ & 4 & & & - & - & - & - & - \\
\hline $\begin{array}{l}\text { Core over } \\
\text { feed(\%) }\end{array}$ & $\uparrow$ & & & & & - & - & \\
\hline $\begin{array}{c}\text { Air pressure } \\
\left(\mathbf{k g f} / \mathbf{c m}^{2}\right)\end{array}$ & $\uparrow$ & & & & 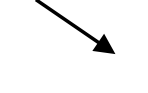 & - & - & \\
\hline $\begin{array}{c}\text { Heater } \\
\text { temp }\left({ }^{\circ} \mathrm{C}\right)\end{array}$ & $\uparrow$ & 4 & - & - & - & - & - & \\
\hline Non-wetted & $\uparrow$ & - & - & - & - & - & - & - \\
\hline
\end{tabular}




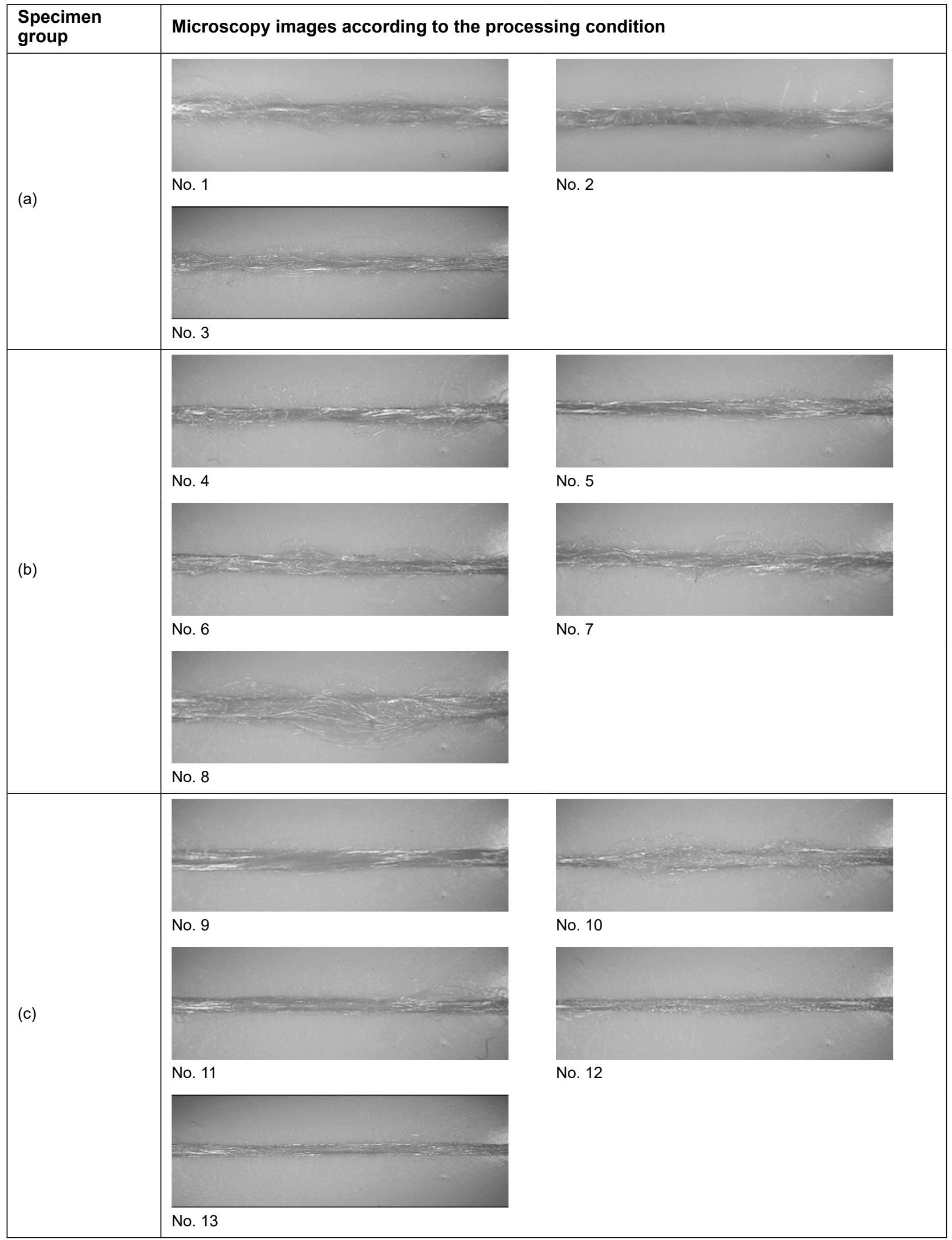

Figure 6. ATY yarn surface profile. 


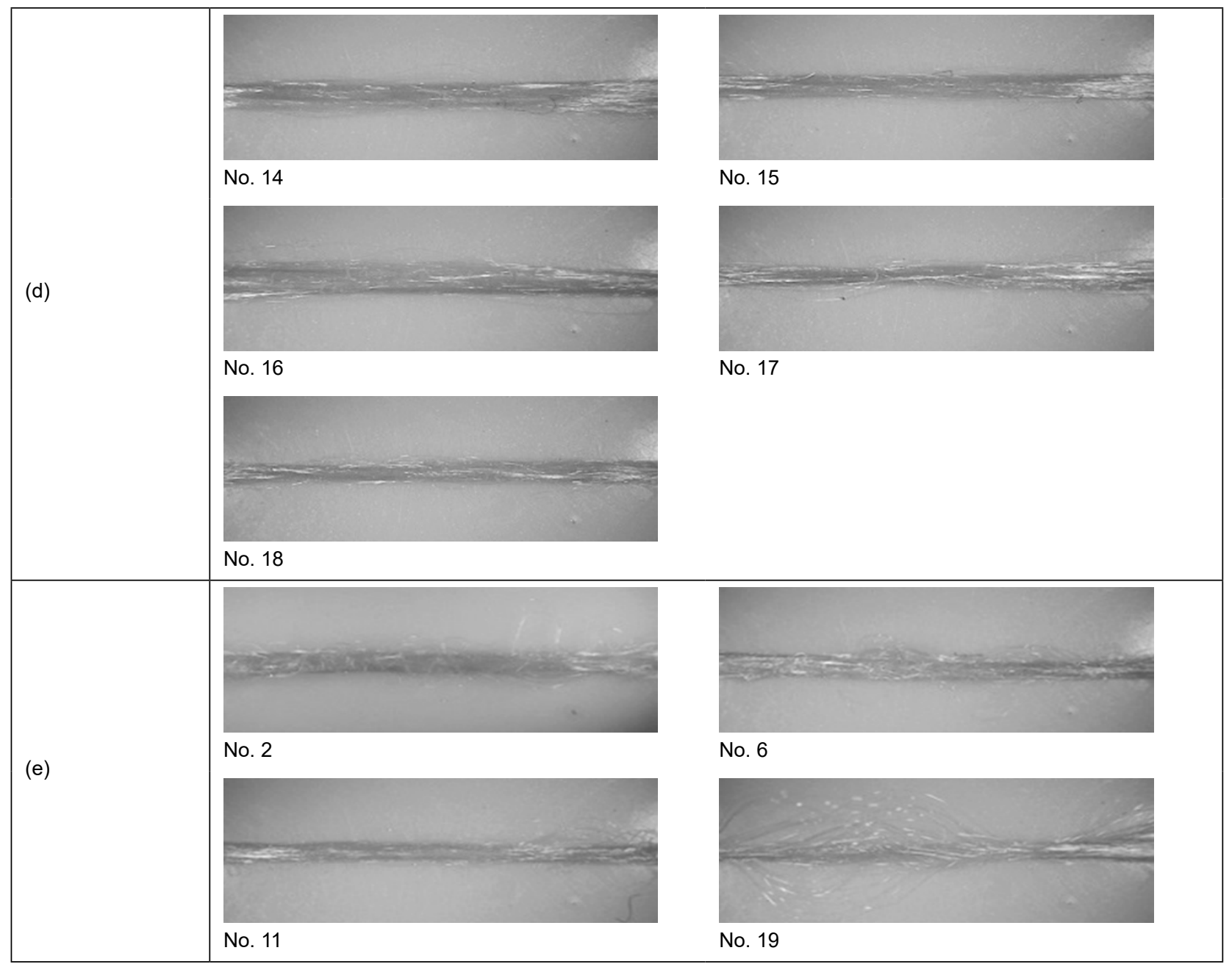

Figure 6. ATY yarn surface profile.

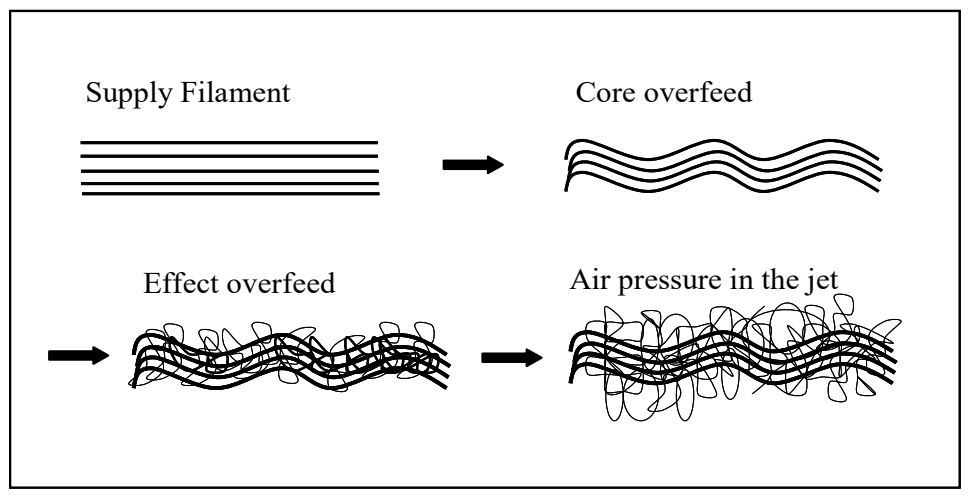

(a)

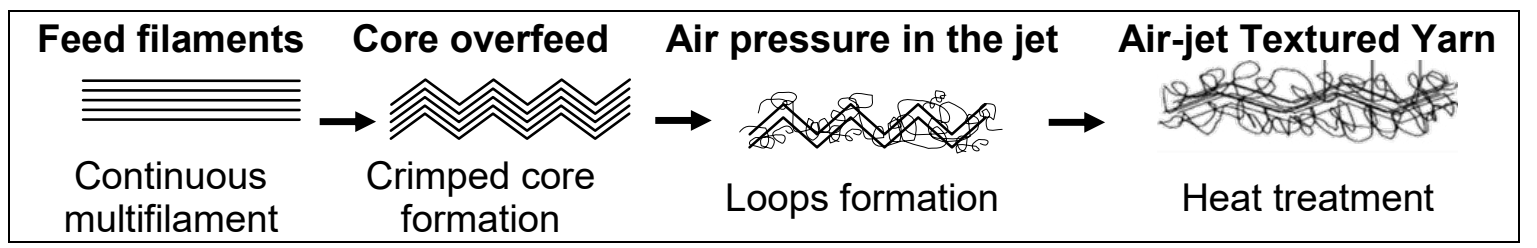

(b)

Figure 7. Proposed para-aramid ATY yarn model. 


\section{CONCLUSIONS}

This study examined the effects of processing parameters on the physical properties of para-aramid air textured yarns. The following conclusions were made.

The core overfeed and air pressure are the main process parameters affecting the physical properties of the aramid ATY. A high core overfeed and air pressure make aramid ATY crimpy in the yarn core and produce entangling fluffy loops on the yarn surface, which result in an increase in the yarn linear density and breaking strain as well as a decrease in the tenacity and initial modulus. In contrast, these yarn physical properties were unaffected by the yarn speed, heater temperature, and wetting treatment, which were attributed to the high yarn mechanical property and thermal resistance of the aramid filament. In addition, the dry and wet thermal shrinkage were unaffected by the process parameters of the aramid ATY. On the other hand, the instability decreased with increasing core overfeed and heater temperature, and increased with increasing air pressure. These results show that a high core overfeed makes the aramid ATY crimpy with an entangling yarn structure, and a high air pressure helps provide small loops on the yarn surface. Finally, a high heater temperature makes the crimpy ATY structure more stable by the strong heat set, which results in low instability. The required physical properties of the para-aramid ATY for protective clothing are a high tenacity and modulus, as well as heat stability and resistance. In addition, good stability to the process tension is required to maintain the entangling fluffy loops made in the ATY process, which produce a good tactile hand and adhesion for protective clothing. Therefore, a low core over feed and air pressure are needed to achieve high tenacity and modulus ATY, and high heater temperature is required to obtain high stability to processing tension.

\section{ACKNOWLEDGEMENTS}

This research was funded by the "Development of multifunctional inorganic particle embedded fibres and high comfort sports/outdoor clothing" project.

\section{References}

[1] Wang, Y., Wiener, J., Militky, J., Mishra, R., \& Zhu, G. (2016). Ozone effect on the properties of aramid fabric. AUTEX Research Journal, DOI : 10.1515/aut-2016-0027.

[2] Kappler, I., Hund, R. D. \& Cherif, C. (2014). Surface modification of carbon fibres using plasma technique. AUTEX Research Journal, 14(1), 34-38.

[3] Bilgin, S., Versteeg, H. K., \& Acar, M. (1996). Effect of nozzle geometry on air-jet texturing performance. Textile Research Journal, 66(2), 83-90.

[4] Sengupta, A. K., Kothari, V. K., \& Sensarma, J. K. (1996). Effects of filament modulus and linear density on the properties of air-jet textured yarns. Textile Research Journal, 66(7), 452-455.

[5] Zhang, J., Zhang, Z., Wang, S., \& Qin, X. (2007). Investigation on air texturing process for diacetate blending with polyester filaments. Fibers and Polymers, 8(4), 427431.
[6] Zhang, J., Zhang, Z., Wang, S., \& Qing, X. (2007). Properties of core-and-effect air textured yarns blended by diacetate and polyester filaments. Fibers and Polymers, 8(1), 84-88.

[7] Rengasamy, R. S., Kothari, V. K., \& Patnaik, A. (2004). Effect of process variables and feeder yarn properties on the properties of core-and-effect and normal air-jet textured yarns. Textile Research Journal, 74(3), 259-264.

[8] Acar, M., Bilgin, S., Versteeg, H. K., Dani, N., \& Oxenham, $W$. (2006). The mechanism of the air-jet texturing: the role of wetting, spin finish and friction in forming and fixing loops. Textile Research Journal, 76(2), 116-125.

[9] Mahish, S. S., Punj, S. K., \& Kothari, V. K. (2010). Comfort and handle related properties of $P N$ blended air-jet textured yarn fabrics. Fibers and Polymers, 11(6), 932-940.

[10] Gudiyawar, M. Y., Kane, C. D., \& Wagh, R. (2011). Effect of blends proportion on the characteristics of dry and pre-wet nylon/viscose blended air-jet textured yarns. Fibers and Polymers, 12(5), 686-691.

[11] Baldua, R. K., Rengasamy, R. S., \& Kothari, V. K. (2015). Effect of feed yarn parameters on air-jet textured yarn properties. Fibers and Polymers, 16(2), 463-470.

[12] Abromavicius, R., \& Milasius, R. (2009). Dependences of air textured polypropylene yarn properties on the yarn structure and air pressure in a texturing jet. Fibres \& Textiles in Eastern Europe, 17(3), 48-50.

[13] Chuah, H. H. (2004). Effect of process variables on bulk development of air $\square$ textured poly (trimethylene terephthalate) bulk continuous filaments. Journal of Applied Polymer Science, 92(2), 1011-1017.

[14] Behtaj, S., Tavanai, H., \& Sadri, S. (2015). Characterisation of air-jet textured yarn structure through image analysis. The Imaging Science Journal, 63(1), 1-6.

[15] Chimeh, M. Y., Tehran, M. A., Latifi, M., \& Mojtahedi, M. R. $M$. (2005). Characterizing bulkiness and hairiness of airjet textured yarn using imaging techniques. The Journal of The Textile Institute, 96(4), 251-255.

[16] Wickramasinghe, G. L. D., \& Foster, P. W. (2015). Effect of nozzle size on texturing performance: comparison between air-jet and steam-jet texturing. The Journal of The Textile Institute, 106(10), 1051-1058.

[17] Wickramasinghe, G. L. D., \& Foster, P. W. (2016). Effects of core-yarn overfeed on texturing performance: comparison between air-jet and steam-jet texturing. The Journal of The Textile Institute, 107(3), 291-299.

[18] Wickramasinghe, G. L. D., \& Foster, P. W. (2015). Investigation of the effect of core-yarn wetting on air-jet and steam-jet spun-like texturing performance. The Journal of The Textile Institute, 106(7), 748-756.

[19] Canoglu, S., Basturk, F., \& Suvari, F. (2014). Investigating the effects of draw ratio, hot-pin temperature, and overfeeding on the color values of air-jet textured polyester yarns. The Journal of The Textile Institute, 105(5), 547552.

[20] Baldua, R. K., Kothari, V. K., \& Rengasamy, R. S. (2014). Effect of feed filament fineness and process parameters on air-jet textured yarns properties. The Journal of The Textile Institute, 105(11), 1186-1192.

[21] Chaithanya, R., Relationship between the processing parameters and tensile properties of air textured Kevlar yarns, M. S. Dissertation, NCSU, North Carolina, Raleigh, 2002. 
[22] Lanston, T. B., The Mechanical behavior of air textured aramid yarns in thermoset composites, M. S. Dissertation, NCSU, North Carolina, Raleigh, 2003.

[23] Dani, N. P. The fundamentals of air-jet texturing, Ph. D. Dissertation, NCSU, North Carolina, Raleigh, 2004.

[24] Alagirusamy, R., \& Ogale, V. (2004). Commingled and air jet-textured hybrid yarns for thermoplastic composites. Journal of Industrial Textiles, 33(4), 223-243.
[25] Mahmood, A. H., Gong, R. H., \& Porat, I. (2013). Development of air textured core-and-effect glass yarns for improving the bonding strength of laminated composites. Fibers and Polymers, 14(2), 271-276.

[26] http://www.kolonindustries.com/Product/product02_06. asp

[27] Kim, H. A., \& Kim, S. J. (2014). Physical properties of para-aramid/nylon hybrid air textured yarns for protective clothing. Fibers and Polymers, 15(11), 2428-2436. 